\title{
Design of a Laboratory Unit Air-Conditioning System with Matlab/Simulink Software
}

\author{
N. KOÇYIĞIT ${ }^{a}$ AND M.E. ŞAHIN ${ }^{b, *}$ \\ ${ }^{a}$ RTE University, Energy Systems Engineering Department, Rize, Turkey \\ ${ }^{b}$ RTE University, Electrical-Electronics Engineering Department, Rize, Turkey
}

\begin{abstract}
In this study, design of an electronic air-conditioning system was carried out using Matlab/Simulink software. The air-conditioning system was designed as a laboratory experimental setup. The aim of this study was to revise and to reuse an outdated air-conditioning laboratory unit, by using improved methods. General equations were defined separately for each part and cell of this air conditioning system. Using these equations Matlab/Simulink models for every component were created. The Matlab/Simulink models were combined and verified with theoretical results. The simulation results show that theoretical results are compatible with the simulation results. These results were tested for input and output air enthalpy values and for humidity values. In addition, air mass flow rates for the number of different fan speeds were compared. The coherent simulation results showed that the general model of the air conditioning system, designed in Matlab/Simulink, behaves correctly. This model will be used in the future studies for comparison of real system results with simulation results.
\end{abstract}

DOI: 10.12693/APhysPolA.132.839

PACS/topics: 07.05.Tp, 07.20.-n, 07.20.Mc

\section{Introduction}

Because of global warming and climate changes, the necessity for the air conditioning systems has become inevitable. Advances in technological processes and efficient design of these systems resulted in more innovative and professional designs.

The air conditioning systems are used for multiple purposes, such as cooling, heating, ventilating etc. [1, 2]. The heating, ventilating and air-conditioning (HVAC) systems are used in residential, commercial, and industrial buildings [3-6].

The typical HVAC systems have one refrigerating system for cooling and dehumidifying, heat pump for heating, humidifying system, and fan for ventilation [7-9]. Such complex structure and the developments in this area require training of the technical staff. Some types of the HVAC units are developed as laboratory experimental setups for training of the technical staff [1].

There was an outdated HVAC laboratory unit, used for studies [1]. The aim of this study is to revise and renovate the outdated HVAC unit by using modeling tools [7]. The aim of current study is to simulate this unit correctly in Matlab/Simulink [10, 11]. Necessary models are simulated and the results are compared with the theory $[5,8,12,13]$.

\section{Definition of the laboratory air-conditioning system}

The HVAC laboratory unit, investigated in this study, was used for training the students and the technical staff.

*corresponding author; e-mail: mustafaerginsahin@yahoo.com
It can perform heating, cooling, humidifying and dehumidifying. The HVAC laboratory unit has a boiler with three electrical resistances for humidifying, a variable air volume blower (fan), two electrical resistances for preheating, a vapour compressed refrigeration system for cooling and dehumidifying, and two electrical resistances for final heating. The picture of laboratory HVAC system and its simplified scheme are shown in Fig. 1a, and $\mathrm{b}$, respectively.

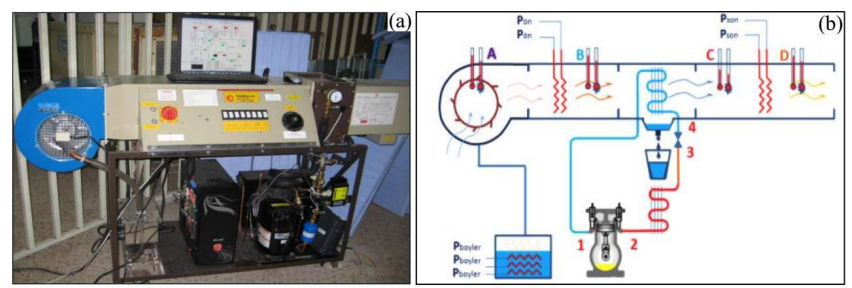

Fig. 1. Air conditioning laboratory setup (a) and its simplified diagram (b).

The HVAC laboratory unit consists of four cells. First of these, is the blower cell for air supply and humidifying, performed in the boiler. Second is the preheating cell. The third is the cooling cell for cooling and dehumidifying the air by using the evaporator. The fourth is the heater cell for reheating air before blowing it into the conditioned space. Each cell is defined by general equations, related with energy and mass balance [7]. Model of the system is created with Matlab/Simulink, using these equations.

\section{System modeling}

In general, air conditioning systems are re-using outside and inside air. Model consists of a single air duct 
system, and air from outside is considered to be an open loop system. The computer model of the physical model of conditioning system is shown in Fig. 2. Pressure transducers, not used in system modeling, have been ignored here.

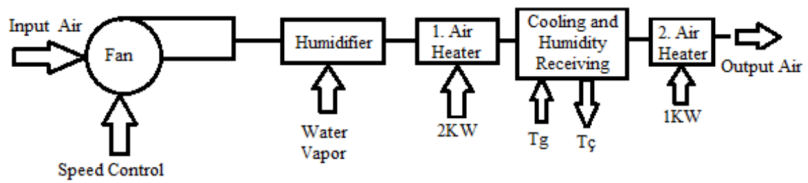

Fig. 2. Laboratory scale physical model of the air conditioning system.

Here the system is assumed to have continuous flow and input and output air mass flow rates are equal, as seen in Eq. (1).

$$
\dot{m}_{\text {in }}=\dot{m}_{\text {out }} \text {. }
$$

Assuming that there is no excess pressure in the conditioned place and that the heated return air fan is not used, the air pressure was assumed to be equal to the outside atmospheric pressure in a fixed space [12].

Air modelling, as function on the fan speed, was performed in Matlab/Simulink, using the required thermodynamic equations of the system, as shown in Fig. 3a. The equations, required for the modelling of fans and humidifiers in Matlab / Simulink, are seen in Fig. 3b.

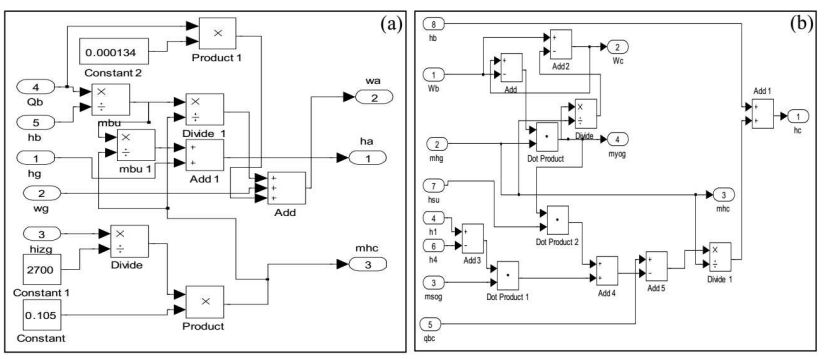

Fig. 3. Matlab/Simulink models of (a) fan and humidifier, (b) cooling and dehumidifying grid.

Using the required thermodynamic equations, the modelling of air heating system was performed in Matlab/Simulink, as shown in Fig. 4.

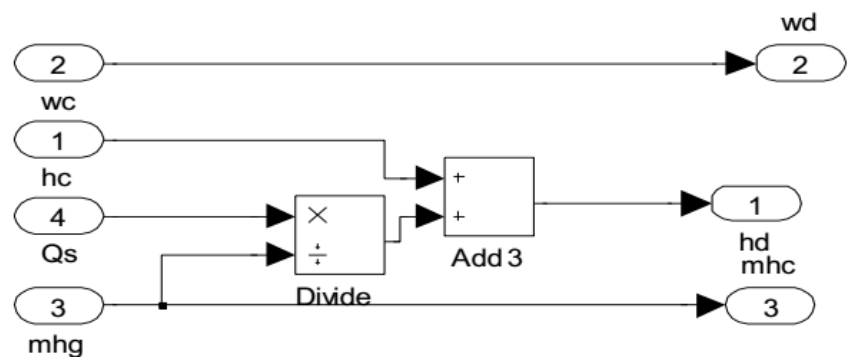

Fig. 4. Matlab/Simulink model of air heating system.

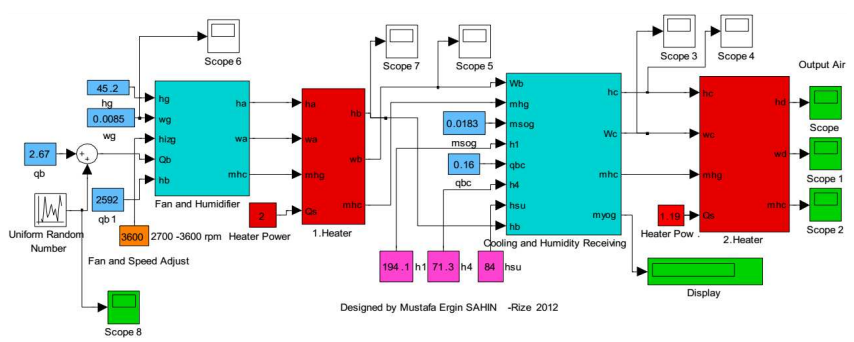

Fig. 5. General pattern of the system, designed in Matlab/Simulink.

Separate blocks of the modelled system, described above, are brought together in Fig. 5 as a general system. The input block of fans and humidifiers are fed with input variables. First heater is fed with $2000 \mathrm{~W}$, and the second heater is fed with $1000 \mathrm{~W}$ of power. Condensate occurring during the cooling and dehumidification and the enclosed temperatures of the system, and other parameters are entered here. Downstream of the input, changes of air humidity and enthalpy, changes of the outlet fan speed and air volume and the effect of heat and humidity, may be also observed. The system parameters which were used in system modelling are given in Table I.

TABLE I

Simulation parameters of air conditioning system.

\begin{tabular}{c|c}
\hline \hline Parameter & Value \\
\hline The enthalpy of the input air $\left(h_{\mathrm{in}}\right)$ & $45.2 \mathrm{~kJ} / \mathrm{kg}$ \\
The humidity of the input air $\left(w_{\mathrm{in}}\right)$ & $0.0085 \mathrm{~kg} / \mathrm{kg}$ \\
The heat given to water $\left(Q_{\mathrm{b}}\right)$ & $2.67 \mathrm{~kW}$ \\
Water enthalpy variation $\left(h_{\mathrm{b}}\right)$ & $2592 \mathrm{~kJ}$ \\
Fan speed $(n)$ & $2700-3600 \mathrm{rpm}$ \\
First heater power $\left(Q_{\mathrm{s}}\right)$ & $2 \mathrm{~kW}$ \\
Second heater power $\left(Q_{\mathrm{s}}\right)$ & $1.19 \mathrm{~kW}$ \\
Specific enthalpy at the exit from evapor. $\left(h_{1}\right)$ & $194.1 \mathrm{~kJ} / \mathrm{kg}$ \\
Specific enthalpy at the inlet into evapor. $\left(h_{4}\right)$ & $71.3 \mathrm{~kJ} / \mathrm{kg}$ \\
Specific enthalpy of water at $20^{\circ} \mathrm{C}\left(h_{\mathrm{water}}\right)$ & $84 \mathrm{~kJ} / \mathrm{kg}$ \\
The mass flow rate of refrigeration $\left(m_{\mathrm{ref}}\right)$ & $0.0183 \mathrm{~kg} / \mathrm{s}$ \\
Heat transfer ratio $\left(Q_{\mathrm{bc}}\right)$ & $0.16 \mathrm{~kW}$ \\
The mass flow rate of air $\left(m_{\text {air }}\right)$ & $0.105 \mathrm{~kg} / \mathrm{s}$ \\
Mass flow rate of condensing water $\left(m_{\text {cond }}\right)$ & $0.000134 \mathrm{~kg} / \mathrm{s}$
\end{tabular}

\section{Simulation results}

The overall system simulation studies of the inputoutput relationships are discussed here. Nonlinear parameters, which can be varied, as temperature and humidity, are assumed constant. Small variations of the parameters are omitted.

Air inlet enthalpy variation is given in Fig. 6a, and the first heater outlet enthalpy is given in Fig. 6b. The enthalpy value of the intake air $h_{\mathrm{a}}$ appears to increase by some amount in the first heating output $h_{\mathrm{b}}$, as expected. These values do not change over time. There are small ripples on the graphics, which cannot be observed. 

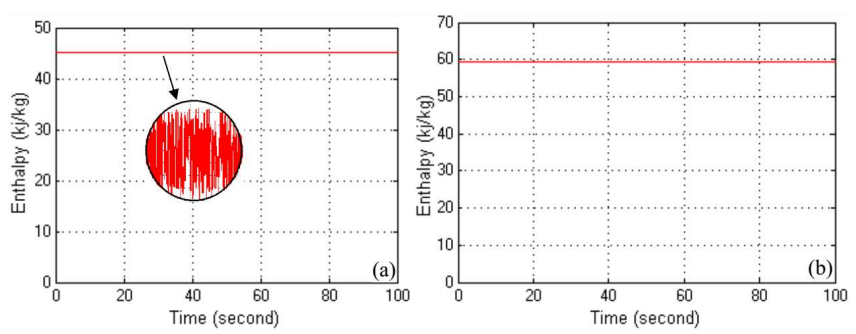

Fig. 6. The enthalpy of the intake air $h_{\mathrm{a}}(\mathrm{a})$ and at the first heating output $h_{\mathrm{b}}(\mathrm{b})$.

Air inlet humidity value is given in Fig. 7a, and humidity value at the humidifier output is given in Fig. $7 \mathrm{~b}$. The humidity ratio of the intake air $w_{g}$ appears to increase by some amount in the humidifier output $w_{\mathrm{a}}$, as expected. These values do not change over time. In the heater outlet the humidity is thought not to change so much.
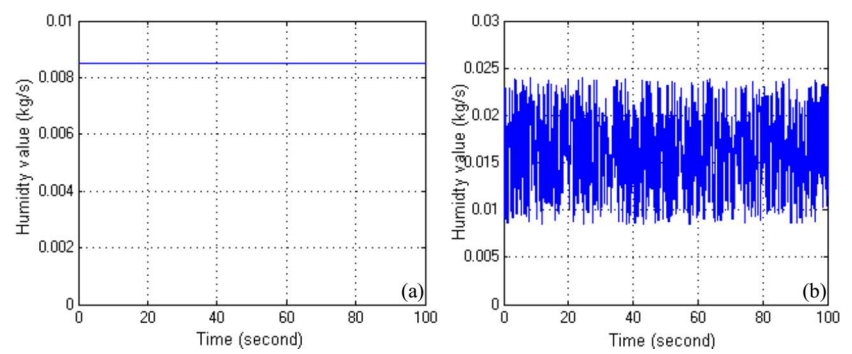

Fig. 7. Humidity $w_{\mathrm{g}}$ at air inlet (a) and at humidifier output $w_{\mathrm{a}}(\mathrm{b})$.

Air enthalpy value of the refrigerant output $h_{\mathrm{c}}$ is shown in Fig. 8a and the enthalpy value at the second air heater output $h_{\mathrm{d}}$ is shown in Fig. 8b. The enthalpies of the air cooler output decrease slightly as expected. The enthalpy of second heater output increases slightly, as was also expected. However, the increase for the second heater output is smaller because the power of this heater is smaller, compared to first heater.
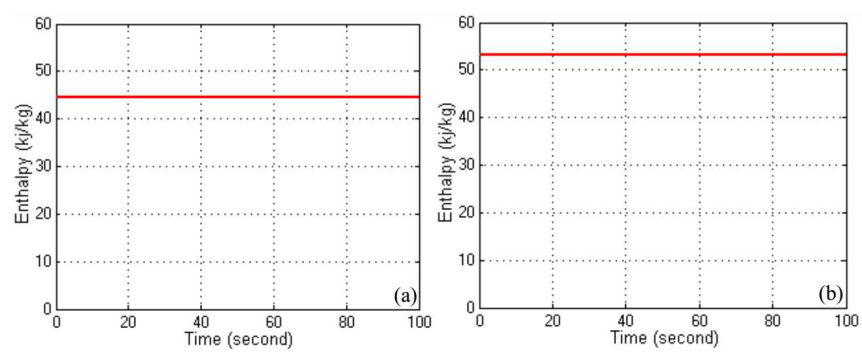

Fig. 8. Enthalpy value of the refrigerant output (a), enthalpy value of the last heater output (b).

Humidity in the cooler exit $w_{\mathrm{c}}$ and the outlet air humidity $w_{\mathrm{d}}$ are shown in Fig. 9a and b, respectively. It appears that the coolant output has decreased a little the amount of moisture, as expected. This change is very small.
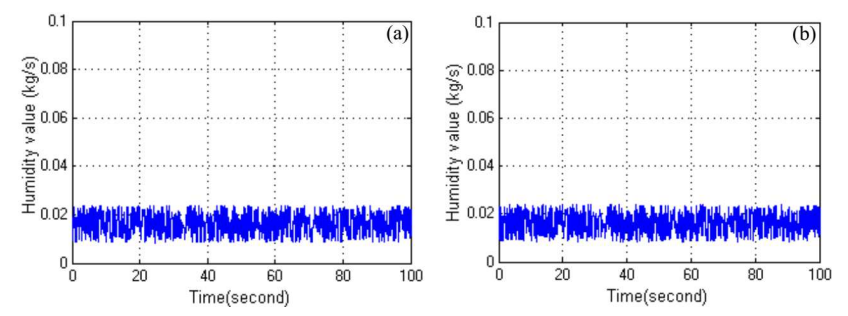

Fig. 9. (a) Humidity in the cooler exit $w_{\mathrm{c}}$, (b) outlet air humidity $w_{\mathrm{d}}$.

The air flow produced at fan speed of $2700 \mathrm{rpm}$ is shown in Fig. 10a, the air flow produced at fan speed of $3600 \mathrm{rpm}$ is shown in Fig. 10b. Here, it is considered to be equal to the inlet air flow and the exhaust air flow, and these results have been observed in simulations. It seems that the speed of air flow had increased with the increasing speed of the fan. The humidity at the air outlet and the value of the enthalpy, depending on the change of the fan speed, are also matters, which need to be investigated.
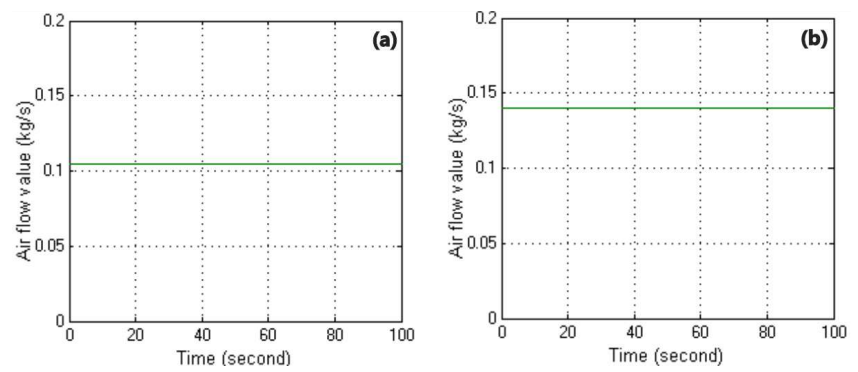

Fig. 10. The air flow $m_{\mathrm{hc}}$, produced at fan speed of $2700 \mathrm{rpm}$ (a) and $3600 \mathrm{rpm}$ (b).

\section{Conclusions}

This study, firstly, examined the structure of the experimental setup for air conditioning. General equations for this air conditioning system were defined separately for each part and cell of the system. Using these equations Matlab/Simulink models for every part were designed. The Matlab/Simulink models were combined and verified with theoretical results. The simulation results showed that the theoretical results are compatible with the simulation results. These results were obtained for input and output air enthalpy values and for humidity values. In addition, air mass flow rates for the number of different fan speeds were compared. The coherent simulation results show that the general model of the air conditioning system, designed in Matlab/Simulink, simulated the real conditions correctly. This model will be used in the future studies for comparison of real system results with simulation results. In addition the system will be further developed using conventional and modern control methods. 


\section{Acknowledgments}

This study was supported by the Scientific Research Unit of RTE University, project no. 2010.101.10.3. The authors wish to thank RTE University for the support.

\section{References}

[1] P.A. Hilton Corporation, Experimental Operating \&5 Maintenance Manual of HVAC 573 Computer Linked Air Conditioning Unit, May 1991, England.

[2] H. Zarabadipour, M. Janalipour, IJRMET 1, 10 (2011).

[3] M. Kocatürk, M.S. Salman, J. Polytechnic 9, 7 (2006).

[4] P. Yeunyongkul, P. Sakulchangsatjatai, P. Terdtoon, Energy Rec. J. 1, 104 (2010).
[5] M. Imal, Acta Phys. Pol. A 130, 245 (2016).

[6] R. Karaali, İ.T. Öztürk, Acta Phys. Pol. A 128, B-279 (2015).

[7] N. Kocyigit, H. Bulgurcu, C-X. Lin, Int. J. Refrigeration 45, 44 (2014).

[8] R. Karaali, Acta Phys. Pol. A 130, 101 (2016).

[9] N. Kocyigit, Int. J. Refrigeration 50, 69 (2015).

[10] M. Şengirgin, E. Pulat, Pamukkale Univ. J. Engin. Sci. 11, 407 (2005).

[11] Mathworks Corporation, Vehicle Electrical and Climate Control Systems, Matlab/Simulik Application Notes, 2015.

[12] Y.A. Çengel, M.A. Boles, Thermodynamics in an engineering approach, Mc-Graw Hill, 1996, p. 470.

[13] R. Karaali, Acta Phys. Pol. A 130, 209 (2016). 